\title{
Hot topic: Comparison of sex-sorted and conventional semen within a fixed-time artificial insemination protocol designed for dairy heifers
}

\author{
D. A. Mallory, ${ }^{*}$ S. L. Lock, $†$ D. C. Woods,† S. E. Poock,ł and D. J. Patterson ${ }^{* 1}$ \\ *Division of Animal Sciences, University of Missouri, Columbia 65211 \\ †Genex Cooperative Inc., Shawano, WI 54166 \\ łDepartment of Veterinary Medicine and Surgery, University of Missouri, Columbia 65211
}

\section{ABSTRACT}

The objective was to compare pregnancy per AI (P/ $\mathrm{AI})$ with conventional $(\mathrm{CON})$ or sex-sorted (SS) semen from a single sire within a fixed-time AI (FTAI) program designed for dairy heifers. Holstein heifers $(\mathrm{n}=$ 240) were assigned to treatment (CON or SS) according to body weight and reproductive tract score. All heifers underwent FTAI by using the "Show-Me-Synch" protocol [controlled internal drug release (CIDR) insert from d 0 to 14 followed by $\mathrm{PGF}_{2 \alpha}$ (25 mg i.m.) $16 \mathrm{~d}$ after insert removal (d 30) with GnRH (100 $\mu \mathrm{g}$ i.m.) and FTAI at $66 \mathrm{~h}$ after $\left.\mathrm{PGF}_{2 \alpha}\right]$. A single professional technician performed the FTAI. Heifers were fitted with heat detection patches at $\mathrm{PGF}_{2 \alpha}$ to characterize estrous response. Estrous response did not differ between $\mathrm{CON}$ $(63 / 120 ; 53 \%)$ and SS $(70 / 120 ; 58 \%)$ treatments. The CON heifers, however, achieved greater FTAI P/AI (82/120; 68\%) compared with SS $(45 / 120 ; 38 \%)$ heifers. The P/AI did not differ for CON heifers that exhibited or failed to exhibit estrus before FTAI [44/63 (70\%) vs. 38/57(67\%), respectively]. For SS heifers, however, those that exhibited estrus had greater $\mathrm{P} / \mathrm{AI}$ compared with those that failed to exhibit estrus [32/70 (46\%) vs. $13 / 50$ (26\%)]. Pregnancy per AI resulting from FTAI was greater for heifers that were inseminated with CON semen compared with those that received SS semen. The expression of estrus before FTAI did not affect P/ AI when CON semen was used, whereas the P/AI with SS semen was greater for heifers detected in estrus. Further studies are required to develop strategies for using sex-sorted semen when inseminating heifers at predetermined fixed times on the basis of expression of estrus before FTAI.

Key words: controlled internal drug release insert, dairy heifer, fixed-time artificial insemination, sexsorted semen

Received June 19, 2012.

Accepted November 11, 2012.

${ }^{1}$ Corresponding author: pattersond@missouri.edu

\section{INTRODUCTION}

Sex-sorted (SS) semen can increase the profitability of dairy farms by increasing the number of genetically superior heifers born after AI (Hohenboken, 1999). Fertility after AI is lower, however, with SS semen than with conventional (CON) semen (Seidel, 2011). The reduced fertility when SS semen is used may be caused by a lower sperm dose compared with CON (approximately 2 million vs. 20 million sperm/dose), in addition to noncompensable damage to sperm cells during the sorting procedure (Catt et al., 1997; Carvalho et al., 2010; DeJarnette et al., 2011). Based on these considerations, synchrony of estrus and ovulation become more critical when using SS semen in conjunction with an estrous synchronization protocol designed to facilitate AI at predetermined fixed times.

The timing between expected ovulation and AI requires careful consideration because the viability of SS sperm is reduced compared with that of CON sperm. Patterson et al. (2011) recently reported a $65 \%$ fixedtime AI (FTAI) pregnancy per AI (P/AI) from field trials involving 2,656 beef heifers that were treated with the "Show-Me-Synch" protocol for FTAI. When compared with alternative controlled internal drug release (CIDR)- or melengestrol acetate (MGA)-based protocols for beef heifers, the Show-Me-Synch protocol had greater synchrony of estrus (Leitman et al., 2009b; Mallory et al., 2010) accompanied by high P/AI resulting from FTAI (Mallory et al., 2011). Although use of SS semen in conjunction with FTAI has not been recommended to date, the repeatability in timing and synchrony of estrus following treatment administration with the Show-Me-Synch protocol (Leitman et al., 2009a,b; Mallory et al., 2010) may provide a sufficient degree of synchrony to facilitate use of SS semen in conjunction with FTAI. These considerations formed the basis of our hypothesis that dairy heifers treated with the Show-Me-Synch protocol would have equivalent $\mathrm{P} / \mathrm{AI}$ after insemination with $\mathrm{SS}$ and $\mathrm{CON}$ semen. 


\section{MATERIALS AND METHODS}

The experiment was conducted at 2 locations within the Doss Dairy Farm (West Plains, MO). Holstein heifers $(\mathrm{n}=140$ at location 1 and $\mathrm{n}=100$ at location 2$)$ were randomly assigned to 1 of 2 treatments (insemination with SS or CON semen). The heifers were blocked by reproductive tract score (RTS; Anderson et al., 1991; Rosenkrans and Hardin, 2003) and BW within location to ensure that treatments were not biased by differences in BW or RTS. All heifers were treated for FTAI by using the Show-Me-Synch protocol (Figure $1)$. The treatment sequence for the protocol is an Eazi-Breed CIDR insert (1.38 g of progesterone; Pfizer Animal Health; New York, NY) from d 0 to 14 followed by an injection of $\mathrm{PGF}_{2 \alpha}(25 \mathrm{mg}$, i.m.; Lutalyse, Pfizer Animal Health) $16 \mathrm{~d}$ after CIDR removal (d 30). An injection of GnRH (100 $\mu \mathrm{g}$, i.m.; Cystorelin, Merial, Athens, GA) was administered concurrently with FTAI at $66 \mathrm{~h}$ after the $\mathrm{PGF}_{2 \alpha}$ injection.

Each heifer was fitted with an Estrotect Heat Detector patch (Rockway Inc., Spring Valley, WI) at the time of $\mathrm{PGF}_{2 \alpha}$. A heifer was defined as having a positive estrous response when an Estrotect patch was completely activated (i.e., all of the scratchable material was worn off). Semen from a single sire (Genex Cooperative Inc., Shawano, WI) that was available as CON and SS was used for FTAI. Semen from a single ejaculate was divided and processed as CON (20 million sperm per straw) or SS (2.1 million sperm per straw). All inseminations were performed by a single professional technician. Pregnancy per AI resulting from FTAI was determined $62 \mathrm{~d}$ after FTAI by using transrectal ultrasonography (Aloka $500 \mathrm{~V}$ ultrasound equipped with a $5.0-\mathrm{MHz}$ linear-array transducer; Hitachi Aloka Medical Corp., Tokyo, Japan). Fetal size (crown-rump measurement $\sim 61 \mathrm{~mm}$ ) and presence of a heart beat were used as determinants of pregnancy via ultrasound on d 62 .

Body weight and RTS were analyzed by ANOVA using the PROC MIXED (SAS Institute Inc., Cary, NC) fitting a normal distribution. Models included the effects of treatment, location, and the interaction of treatment and location. Means are reported as least square means \pm standard errors. Pregnancy per AI was analyzed by logistic regression using PROC GENMOD with a binomial distribution using the link function of logit. The model included the main effects of location, treatment, estrous response, and interactions.

\section{RESULTS AND DISCUSSION}

We observed an effect of location on heifer BW because heifers at location 2 were heavier $(P<0.01)$ than heifers at location $1(413 \pm 2.7$ vs. $352 \pm 2.3 \mathrm{~kg})$. However, location had no effect on RTS $(4.5 \pm 0.1$;
$P=0.33)$. Body weight $(P=0.99)$ and RTS $(P=$ $0.20)$ were similar for heifers assigned to CON and SS treatments. Estrous response did not differ $(P=0.20)$ between heifers assigned to CON $(63 / 120,53 \%)$ or SS $(70 / 120,58 \%)$ groups (Table 1). Heifers inseminated with CON semen had greater $(P<0.001) \mathrm{P} / \mathrm{AI}$ compared with heifers inseminated with SS semen (Table 1). Heifers that exhibited estrus before FTAI tended ( $P$ $=0.06$ ) to have greater $\mathrm{P} / \mathrm{AI}$ than heifers that failed to exhibit estrus. Pregnancy per AI was similar for heifers inseminated with CON semen that were either observed or not observed in estrus (Table 1). Conversely, heifers that were inseminated with SS semen that exhibited estrus had greater $(P=0.04) \mathrm{P} / \mathrm{AI}$ after FTAI compared with heifers that failed to exhibit estrus (Table 1). We acknowledge that by using a single ejaculate from a single sire, results are restricted to that particular individual. Semen from different bulls responds differently to the sorting process; therefore, it is possible that interpretation of these results may differ when using a different sire, supporting the need for future research.

Sex-sorted semen is currently recommended for use only after an observed estrus. Expanded use of sexsorted semen in many cases, however, will rely on development of protocols that facilitate its use in conjunction with FTAI. Pregnancy per AI resulting from FTAI using conventional semen in heifers is expected to be greater following treatment with long-term CIDRbased protocols because of improvements in synchrony of estrus following treatment compared with short-term CIDR-based or melengestrol acetate-based protocols (Busch et al., 2007; Mallory et al., 2011). Although synchrony of estrus was not measured in this study, our results and those reported previously by Mallory et al. (2011) demonstrate that the Show-Me-Synch protocol is effective in facilitating FTAI in both beef and dairy heifers when conventionally processed semen is used. The high $\mathrm{P} / \mathrm{AI}$ for $\mathrm{CON}$ semen observed in

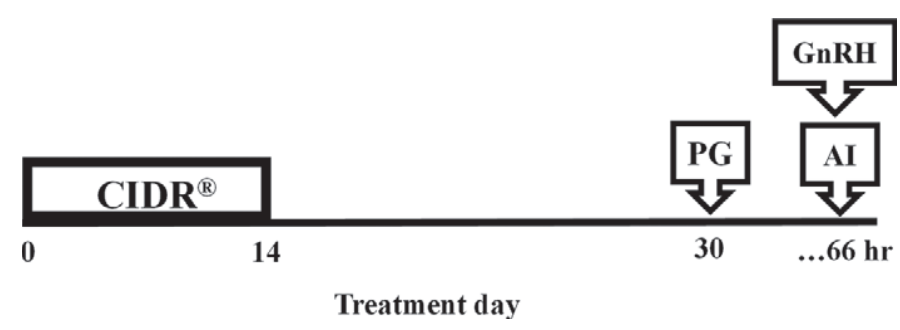

Figure 1. Fixed-time AI protocol (Show-Me-Synch) used to synchronize heifers before insemination with conventional or sex-sorted semen. The protocol used an Eazi-Breed controlled internal drug release (CIDR) insert (1.38 g of progesterone; Pfizer Animal Health, New York, NY) from d 0 to 14 followed by $\mathrm{PGF}_{2 \alpha}$ (PG; $25 \mathrm{mg}$, i.m. Lutalyse; Pfizer Animal Health) 16 d later. Heifers were treated with GnRH (100 $\mu \mathrm{g}$, i.m. Cystorelin; Merial, Athens, GA) and inseminated with conventional or sex-sorted semen at $66 \mathrm{~h}$ after $\mathrm{PGF}_{2 \alpha}$ administration. 
Table 1. Pregnancy per AI after fixed-time AI with conventional and sex-sorted semen for heifers at 2 locations that were either observed in estrus or not observed in estrus before AI

\begin{tabular}{|c|c|c|c|c|c|c|}
\hline \multirow[b]{2}{*}{ Estrus } & \multicolumn{2}{|c|}{ Conventional } & \multicolumn{2}{|c|}{ Sex-sorted } & \multicolumn{2}{|c|}{ Combined } \\
\hline & Proportion & $\%$ & Proportion & $\%$ & Proportion & $\%$ \\
\hline \multicolumn{7}{|l|}{ Location 1} \\
\hline Yes & $28 / 43$ & 65 & $22 / 41$ & $54^{\mathrm{a}}$ & $50 / 84$ & 60 \\
\hline No & $18 / 27$ & $67^{\mathrm{c}}$ & $8 / 29$ & $28^{\mathrm{b}, \mathrm{d}}$ & $26 / 56$ & 46 \\
\hline Total (yes + no) & $46 / 70$ & $66^{\mathrm{c}}$ & $30 / 70$ & $43^{\mathrm{d}}$ & $76 / 140$ & 54 \\
\hline \multicolumn{7}{|l|}{ Location 2} \\
\hline Yes & $16 / 20$ & $80^{\mathrm{c}}$ & $10 / 29$ & $34^{\mathrm{d}}$ & $26 / 49$ & 53 \\
\hline No & $20 / 30$ & $67^{\mathrm{c}}$ & $5 / 21$ & $24^{\mathrm{d}}$ & $25 / 51$ & 49 \\
\hline Total $($ yes + no $)$ & $36 / 50$ & $72^{\mathrm{c}}$ & $15 / 50$ & $30^{\mathrm{d}}$ & $51 / 100$ & 51 \\
\hline \multicolumn{7}{|l|}{ Combined } \\
\hline Yes & $44 / 63$ & $70^{\mathrm{c}}$ & $32 / 70$ & $46^{\mathrm{a}, \mathrm{d}}$ & $76 / 133$ & $57^{\mathrm{x}}$ \\
\hline No & $38 / 57$ & $67^{\mathrm{c}}$ & $13 / 50$ & $26^{\mathrm{b}, \mathrm{d}}$ & $51 / 107$ & $48^{\mathrm{y}}$ \\
\hline Total (locations $1+2$ ) & $82 / 120$ & $68^{c}$ & $45 / 120$ & $38^{\mathrm{d}}$ & $127 / 240$ & 53 \\
\hline
\end{tabular}

${ }_{\mathrm{a}, \mathrm{b}}$ Means within columns with different superscripts differ $(P<0.05)$.

${ }^{c, d}$ Means within rows with different superscripts differ $(P<0.01)$.

${ }^{\mathrm{x}, \mathrm{y}}$ Means within columns with different superscripts tend to differ $(P=0.06)$.

the current study did not depend on the expression of estrus. For SS semen, P/AI resulting from FTAI was greater among heifers that exhibited estrus before insemination. The fertility percentage (SS compared with $\mathrm{CON})$, however, was markedly lower than that reported by DeJarnette et al. (2009), supporting the need to more closely match timing of insemination with estrus expression. This suggests that the timing of FTAI following administration of the Show-Me-Synch protocol should be evaluated more carefully for heifers inseminated with SS semen so that insemination and estrus expression are more closely matched. Re-evaluation of the timing of insemination in situations involving FTAI following administration of the Show-Me-Synch protocol may result in improvements in $\mathrm{P} / \mathrm{AI}$ in breeding programs involving SS semen. Although further studies are needed, perhaps a sensible approach to follow when FTAI is preferred is to use SS semen for those heifers that exhibit estrus and to use less expensive conventional semen when FTAI is performed for heifers that fail to exhibit estrus.

\section{ACKNOWLEDGMENTS}

The authors gratefully acknowledge Doss Dairy Farm (West Plains, MO) for providing the heifers used in this experiment; Pfizer Animal Health (New York, NY) for providing the Lutalyse sterile solution and Eazi-Breed CIDR cattle inserts; Merial (Athens, GA) for providing the Cystorelin; and Genex Cooperative Inc. (Shawano, WI) for providing the semen.

\section{REFERENCES}

Anderson, K. J., D. LeFever, J. S. Brinks, and K. G. Odde. 1991. The use of reproductive tract scoring in beef heifers. Agric. Pract. 12:19-26.

Busch, D. C., D. J. Wilson, D. J. Schafer, N. R. Leitman, J. K. Haden, M. R. Ellersieck, M. F. Smith, and D. J. Patterson. 2007. Com- parison of CIDR-based protocols to synchronize estrus prior to fixed-time AI in beef heifers. J. Anim. Sci. 85:1933-1939.

Carvalho, J. O.. R. Sartori, G. M. Machado, G. B. Mourao, and M. A. N. Dode. 2010. Quality assessment of bovine cryopreserved sperm after sexing by flow cytometry and their use in in vitro embryo production. Theriogenology 74:1521-1530.

Catt, S. L., L. K. O'Brien, W. M. C. Maxwell, and G. Evans. 1997. Assessment of ram and boar spermatozoa during cell-sorting by flow cytometry. Reprod. Domest. Anim. 32:251-258.

DeJarnette, J. M., M. A. Leach, R. L. Nebel, C. E. Marshall, C. R. McCleary, and J. F. Moreno. 2011. Effects of sex-sorting and sperm dosage on conception rates of Holstein heifers: Is comparable fertility of sex-sorted and conventional semen plausible? J. Dairy Sci. 94:3477-3483.

DeJarnette, J. M., R. L. Nebel, and C. E. Marshall. 2009. Evaluating the success of sex-sorted semen in US dairy herds from on farm records. Theriogenology 71:49-58.

Hohenboken, W. D. 1999. Applications of sexed semen in cattle production. Theriogenology 52:1421-1433.

Leitman, N. R., D. C. Busch, D. A. Mallory, D. J. Wilson, M. R. Ellersieck, M. F. Smith, and D. J. Patterson. 2009a. Comparison of long-term CIDR-based protocols to synchronize estrus in beef heifers. Anim. Reprod. Sci. 114:345-355.

Leitman, N. R., D. C. Busch, D. J. Wilson, D. A. Mallory, M. R. Ellersieck, M. F. Smith, and D. J. Patterson. 2009b. Comparison of controlled internal drug release insert-based protocols to synchronize estrus in prepubertal and estrous-cycling beef heifers. J. Anim. Sci. 87:3976-3982.

Mallory, D. A., J. M. Nash, M. R. Ellersieck, M. F. Smith, and D. J. Patterson. 2011. Comparison of long-term progestin-based protocols to synchronize estrus prior to fixed-time artificial insemination in beef heifers. J. Anim. Sci. 89:1358-1365.

Mallory, D. A., D. J. Wilson, D. C. Busch, N. R. Leitman, M. R. Ellersieck, M. F. Smith, and D. J. Patterson. 2010. Comparison of long-term progestin-based estrus synchronization protocols in beef heifers. J. Anim. Sci. 88:3568-3578.

Patterson, D. J., D. A. Mallory, J. M. Nash, N. T. Martin, and M. F. Smith. 2011. Strategies to optimize use of AI in cow/calf production systems: Focus on fixed-time AI protocols for heifers. Pages 11-40 in Proc. Appl. Reprod. Strat. Beef Cattle, Joplin, MO. University of Missouri, Columbia.

Rosenkrans, K. S., and D. K. Hardin. 2003. Repeatability and accuracy of reproductive tract scoring to determine pubertal status in beef heifers. Theriogenology 59:1087-1092.

Seidel, G. E. 2011. Profitable uses of sex-sorted semen. Pages 349-352 in Proc. Appl. Reprod. Strat. Beef Cattle, Joplin, MO. University of Missouri, Columbia. 